\title{
STUDIES OF GASTRIC PEPSIN. I. METHODS OF MEASUREMENT AND FACTORS WHICH INFLUENCE IT
}

\author{
BY ARNOLD E. OSTERBERG, FRANCES R. VANZANT ' \\ AND WALTER C. ALVAREZ \\ (From the Section on Chemistry and the Division of Medicine, The Mayo Clinic, \\ Rochester, Minn.)
}

(Received for publication December 23, 1932)

The study of gastric pepsin has failed to receive adequate consideration for several reasons, but mainly because of the lack of technic for obtaining reliable measurements. We investigated the method originally proposed by Gates (1) and more fully elaborated by Gilman and Cowgill (2), and found it to be accurate and highly satisfactory. In fact, it is more accurate than is needed in clinical practice. We have used this method, with slight modifications, in the investigations reported in this and the following paper. The details of the technic can be obtained from the original article by Gilman and Cowgill (2). In this method one measures the rate of digestion of gelatin from an exposed and developed photographic film. As digestion proceeds, the silver granules in the gelatin are liberated, and the resulting decrease in opacity of the film is taken as a measure of the digestion which has occurred.

\section{TECHNIC}

We use, for the digestion, a cell $11 \mathrm{~mm}$. in diameter and $1.2 \mathrm{~mm}$. in depth turned out of sheet bakelite on a lathe. Its capacity is approximately $0.5 \mathrm{cc}$. The solution to be tested, diluted with an equal volume of glycine hydrochloric acid buffer of $\mathrm{pH} \mathrm{2,} \mathrm{is} \mathrm{placed} \mathrm{in} \mathrm{the} \mathrm{cell.} \mathrm{A} \mathrm{small}$ square of the prepared film is then laid over the top of the cell and this is covered by a glass square. The whole is clamped together by means of a spring clothes pin and placed in a water bath the temperature of which is maintained at $25^{\circ} \mathrm{C}$. After fifteen minutes the film is removed, washed, and dried, and the change in opacity is determined with a colorimeter. The standard for comparison is a freshly prepared suspension of colloidal silver. The index of peptic digestion is obtained by the use of a nomogram as described by Gilman and Cowgill (2).

${ }^{1}$ Fellow Josiah Macy, Jr. Foundation, on duty at The Mayo Foundation, Rochester, Minnesota. 


\section{The Unit of Measurement}

We have not found it necessary to conduct the determinations in triplicate because of the close agreement of duplicate determinations. Softening of the film due simply to moistening with the solution causes an error of approximately 70 units which must be subtracted from each determination. Since films prepared at different times may differ slightly in this respect, it is well to determine the correction for each lot of film prepared.

The unit of pepsin arbitrarily established by Gilman and Cowgill represents the proteolytic activity of a $1: 1,000,000,000$ solution of a theoretically pure pepsin. They arrived at this unit by assuming that a 1 per cent solution of Armour's 1:10,000 pepsin powder contains 1,000 units.

Because of possible variations in the strength of different lots of the commercial pepsin used it is well always to standardize each new lot against the one previously employed. It has been our experience that a solution of commercial pepsin is not sufficiently stable to be used from day to day. The standard must therefore be prepared each time determinations are to be made. The pepsin in the gastric contents of man and dogs is much more stable, and retains its strength for at least a week if kept at ice box temperature.

Before taking up a systematic study of gastric pepsin in various diseases it was necessary first to determine the best conditions for obtaining the juice for analysis. First we studied the residuum aspirated in the morning, before taking food or drink, but we found the concentration of pepsin in such juice so variable that single determinations had little value. Actually in specimens from twenty-four normal, fasting persons it varied from 5 to 1,930 units, with an average of 388 units. This extreme variability is doubtless due to the variation in the size of the fractions of swallowed saliva, regurgitated duodenal secretion, and gastric juice which make up the material obtained. In subsequent work we used gastric contents removed one hour after the taking of eight arrowroot cookies and $400 \mathrm{cc}$. of water. We examined, in this way, juice from eighty-five persons whom we believed to be normal inasmuch as they had no complaint referable to the upper part of the digestive tract, or disease which might affect gastric secretion. Considerable variation existed in the content of pepsin, the value ranging from 0 to 580 units. The modal or most typical value was about 100 units. The arithmetic mean was distinctly higher than this, due to a few high readings. For the entire group the mean was 145 units, with a standard deviation of 125 units. From Figure 1 it can be seen that the men had slightly higher values than the women. This is in accord with the higher acidity in males which has previously been demonstrated (3). Although the variability in the read- 
ings obtained after an Ewald type of meal is high, it is considerably less than that found with juice of fasting subjects.

An effort was made to determine the range of variation in repeated estimations in the case of one individual. Eight determinations made on successive days in a case of pseudo-ulcer associated with high pepsin readings ranged from 610 to 1,930 units, giving a mean value of 1,175 and a standard deviation of 480 units. In this case seventeen estimations of pepsin in the fasting juice ranged from 410 to 2,530 units, giving a

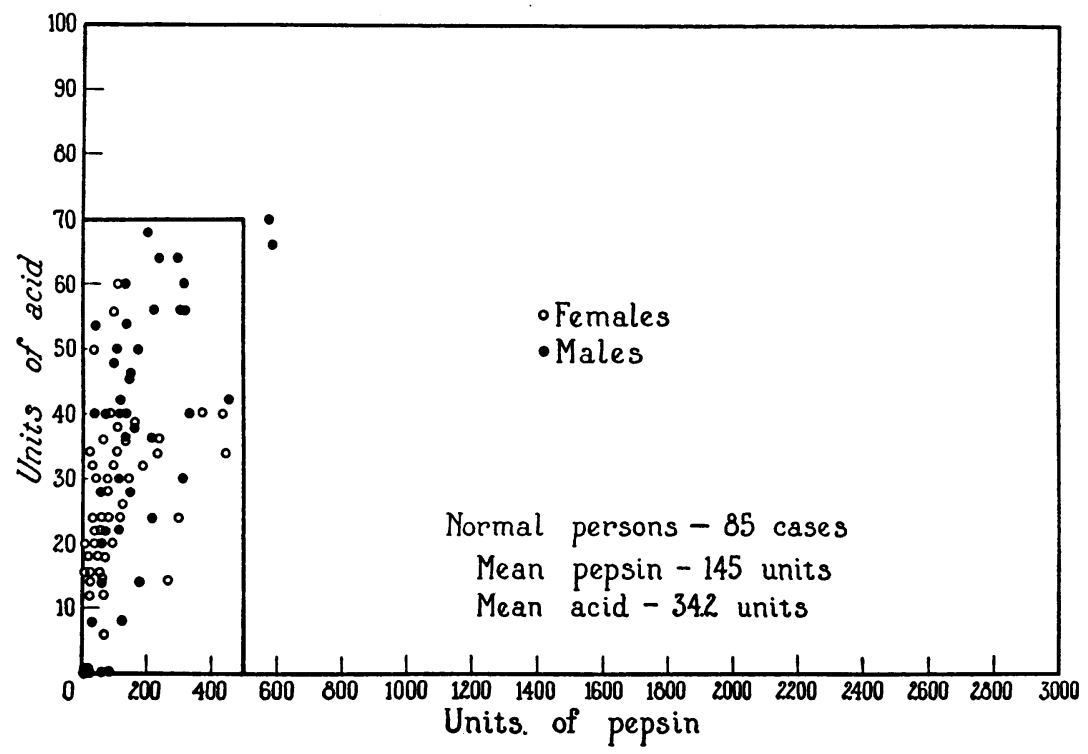

Fig. 1. Distribution of Concentrations of Acid and Pepsin after Ewald Type of Test Meal in Eighty-five Normal Persons

The brackets indicate normal limits for acid and pepsin.

mean of 1,319, and a standard deviation of 592 units. Repeated tests on the gastric residuums from a group of twenty-three patients, and a similar study of juice obtained after test meals given to three patients showed somewhat less variability. In the face of such marked variations in the values obtained from one person when examined on several days, it is obvious that before one can call any reading abnormal it must be well beyond the range of normal figures.

\section{Effect of Contaminants}

Before one can evaluate differences in concentration of pepsin it is necessary to know what effect, if any, is likely to be produced by the presence of a number of common contaminants of the gastric juice. The necessary investigations were made both in vitro and in vivo. The sub- 
stances which we felt might be of some importance because of their frequent occurrence in gastric contents were bile, bilirubin, mucin, blood and its several constituents such as plasma, serum, erythrocytes and crystalline hemoglobin, protein in the form of egg albumen, and peptones. As can be seen in Table 1, all of these substances caused more or less reduction in peptic activity.

TABLE 1

The effect of various substances on the activity of pepsin solution *

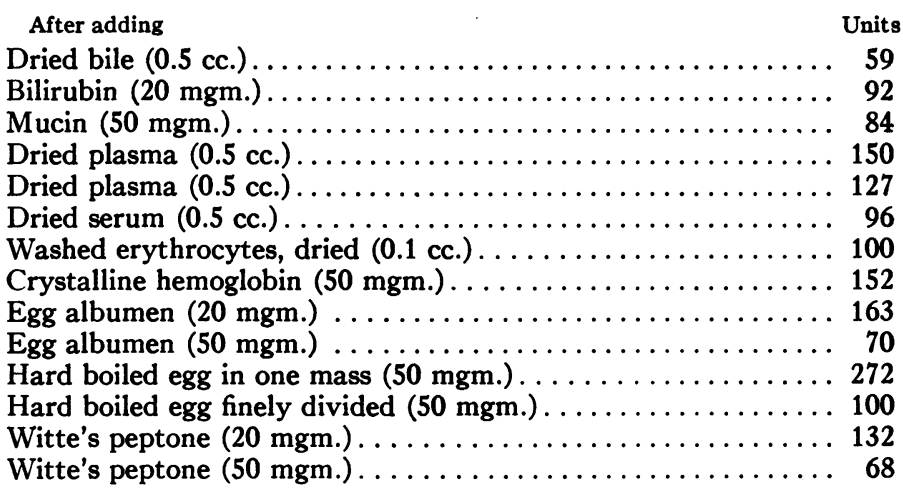

* In each experiment a weighed amount of the substance to be tested was added to $1 \mathrm{cc}$. of a solution of pepsin, the activity of which corresponded to 500 units. The figures represent the depressed values obtained after incubation. The amount of injury to peptic activity was represented in each case by the difference between the reading obtained and 500 .

It is often stated in the literature that the presence of blood in the gastric contents will decrease proteolytic activity, and that this is due to an antipepsin. Table 2 shows that the ingestion of blood markedly lowered the proteolytic power of gastric contents, but this effect was followed by a stimulation of secretion which soon compensated for the preliminary drops. Since a similar effect was produced by raw liver, and also by beef extract, it is doubtful if the decrease of peptic activity in the presence of blood is due to a specific antipepsin. The same decrease may be found in vitro after the addition of crystalline hemoglobin or other fairly pure constituents of the blood (Table 1). The degree of reduction in activity seems to be roughly a function of the amount of organic material added. The possibility presents itself that the decrease may be due simply to an adsorption which results in the removal of pepsin from solution.

As is well known, the effect of raising the $\mathrm{pH}$ is to reduce peptic activity, and an alkaline reaction actually destroys much of the ferment. The effect of alkali when taken into the stomach of a human being is shown in Table 2, experiment 5. Following the ingestion of two Sippy 
TABLE 2

Experiments in vivo on a patient with a high peptic value

Experiment 1

Fasting specimen $\ldots \ldots \ldots \ldots \ldots \ldots \ldots \ldots \ldots \ldots \ldots \ldots \ldots \ldots \ldots \ldots$

Thirty minutes after ingestion of 5 cc. of dried cow's blood in capsule . . . . . . 620

Sixty minutes after ingestion of 5 cc. of dried cow's blood in capsule . . . . . . . 510

Ninety minutes after ingestion of 5 cc. of dried cow's blood in capsule . . . . . . 820

One hundred twenty minutes after ingestion of 5 cc. of dried cow's blood in capsule 820

Experiment 2

Fasting specimen . . . . . . . . . . . . . . . . . . . . . . . . . 1850

Thirty minutes after ingestion of 10 cc. of human blood . . . . . . . . . . . 184

Thirty minutes after ingestion of second $10 \mathrm{cc}$. of human blood . . . . . . . 910

Experiment 3

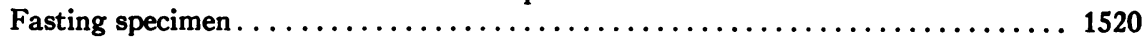

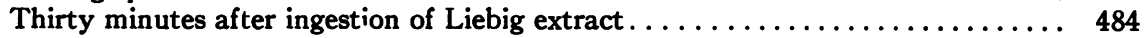

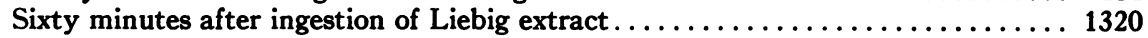

Ninety minutes after ingestion of Liebig extract . . . . . . . . . . . . . 810

One hundred twenty minutes after ingestion of Liebig extract . . . . . . . . 1520

Experiment 4

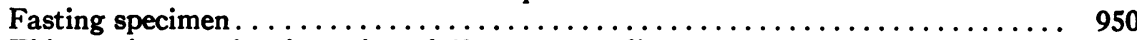

Thirty minutes after ingestion of 60 grams raw liver $\ldots \ldots \ldots \ldots \ldots \ldots \ldots \ldots \ldots \ldots$

Sixty minutes after ingestion of 60 grams raw liver $\ldots \ldots \ldots \ldots \ldots \ldots \ldots \ldots$

Ninety minutes after ingestion of 60 grams raw liver. . . . . . . . . . . 514

One hundred twenty minutes after ingestion of 60 grams raw liver. . . . . . 734

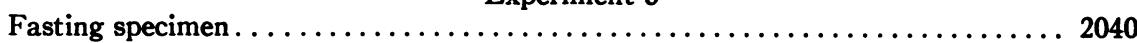

Thirty minutes after ingestion of two Sippy tablets $\ldots \ldots \ldots \ldots \ldots \ldots \ldots \ldots \ldots \ldots \ldots .2040$

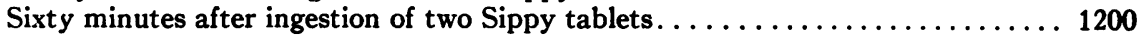

tablets, containing a total of 30 grains ( 2 grams) of calcium carbonate and 20 grains (1.30 gram) of sodium bicarbonate, peptic activity was markedly decreased, and the return to the previous reading was slow. This depressing effect of the alkali was the more striking because the experiment was performed on a subject whose normal peptic activity is unusually marked.

\section{SUMMARY}

It has been found that the Gates method (1) as modified by Gilman and Cowgill (2) gives accurate and reproducible values for the proteolytic activity of a specimen of gastric contents.

The variability in readings obtained when successive specimens of fasting residuum from the same subject were used was so great as to destroy their clinical value. More consistent results were obtained with juice obtained after an Ewald type of meal. Standards of normal for pepsin after this type of test meal are published in this paper.

Bile, mucin, blood proteins, albumin, peptones, and alkalies markedly reduced peptic activity. The fact that these substances may modify 
peptic activity must be kept in mind in making a clinical study of gastric pepsin.

\section{BIBLIOGRAPHY}

1. Gates, F. L., Proc. Soc. Exper. Biol. and Med., 1927, xxiv, 936. A Method of Proteolytic Enzyme Titration.

2. Gilman, Alfred and Cowgill, G. R., J. Biol. Chem., 1930, lxxxviii, 743. The Determination of Peptic Activity: an Examination and Application of the Gates Method of Proteolytic Enzyme Titration.

3. Vanzant, Frances R., Alvarez, W. C., Eusterman, G. B., Dunn, H. L., and Berkson, Joseph, Arch. Int. Med., 1932, xlix, 345. The Normal Range of Gastric Acidity from Youth to Old Age: an Analysis of 3,746 Records. 